\title{
Is There an Association Between Hemoglobin A1C and Deep Postoperative Infection After TKA?
}

\author{
Jourdan M. Cancienne MD, Brian C. Werner MD, James A. Browne MD
}

Received: 2 October 2016/Accepted: 12 January 2017/Published online: 23 January 2017

(C) The Association of Bone and Joint Surgeons (B) 2017

\begin{abstract}
Background Despite substantial research into the use of glycemic markers to stratify infection risk in patients with diabetes mellitus, there is little evidence to support a perioperative hemoglobin A1c (HbA1c) level associated with an increased risk of deep postoperative infection after TKA.

Questions/Purposes (1) Is there an association between perioperative $\mathrm{HbAlc}$ level in patients with diabetes and deep postoperative infection after primary TKA? (2) Is the perioperative HbA1c level in patients with diabetes a useful test as an independent predictor for postoperative infection after TKA?

Methods We queried the PearlDiver Patient Records Database Humana dataset for patients who underwent primary TKA. This is a for-fee insurance patient-records database that contains records for more than 20 million patients with orthopaedic diagnoses from 2007 to the second quarter of 2015. The data for patients from this study
\end{abstract}

Each author certifies that he has no commercial associations (eg, consultancies, stock ownership, equity interest, patent/licensing arrangements, etc) that might pose a conflict of interest in connection with the submitted article.

All ICMJE Conflict of Interest Forms for authors and Clinical Orthopaedics and Related Research ${ }^{\circledR}$ editors and board members are on file with the publication and can be viewed on request.

Each author certifies that his institution approved or waived approval for the human protocol for this investigation and that all investigations were conducted in conformity with ethical principles of research

J. M. Cancienne, B. C. Werner ( $\square)$, J. A. Browne

Department of Orthopaedic Surgery, University of Virginia

Health System, PO Box 800159 HSC, Charlottesville,

VA 22908, USA

e-mail: bcw4x@virginia.edu were taken from the Humana dataset since this is the only insurer that includes laboratory data among the available databases. Although it is difficult to calculate attrition in this database, in the current study the minimum number of patients with at least 1 year followup was $86 \%$. Patients with diabetes who had an HbA1c level obtained within 3 months of surgery were identified, stratified based on their $\mathrm{HbA} 1 \mathrm{c}$ level in $0.5 \mathrm{mg} / \mathrm{dL}$ increments, and then compared with patients with diabetes without an HbA1c level within 3 months of surgery. Patients who had an HbAlc level within 3 months of surgery had slightly higher rates of polyneuropathy, chronic renal failure, and chronic kidney disease Stages 2 and 3. Otherwise, these groups were similar regarding rates of peripheral vascular disease, microvascular ischemic disease, metabolic syndrome, gastroparesis, end stage renal disease, age, and gender. Deep infection was defined as an infection resulting in operative intervention within 1 year of the primary TKA, and the incidence of such intervention for each $\mathrm{HbAlc}$ group then was identified. A receiver operating characteristic (ROC) analysis was performed to determine a threshold value of the $\mathrm{HbA1c}$, and an area under the curve (AUC) analysis was performed to measure the accuracy and clinical utility of $\mathrm{HbAlc}$ as an independent predictor for postoperative infection.

Results The rate of infection requiring operative intervention ranged from a low of $0.8 \%$ with an HbA1c of 5.49 $\mathrm{mg} / \mathrm{dL}$ or less, up to $3.5 \%$ for patients with $\mathrm{HbA} 1 \mathrm{c}$ level greater than $11.5 \mathrm{mg} / \mathrm{dL}$. The ROC analysis indicated that the best threshold was an $\mathrm{HbA1c}$ of $8.0 \mathrm{mg} / \mathrm{dL}(1.7 ; 95 \%$ CI, $1.2-2.4 \mathrm{mg} / \mathrm{dL} ; \mathrm{p}=0.004)$, however, the AUC of 0.548 $(95 \%$ CI, 0.50-0.59; $\mathrm{p}=0.025)$ indicated that this threshold was inaccurate and only slightly better than chance, and thus alone could not serve as an independent discriminator of infection risk. 
Conclusions The risk of deep postoperative infection requiring surgical intervention after TKA in patients with diabetes mellitus increases as the perioperative HbA1c increases. While a threshold HbA1c level of $8.0 \mathrm{mg} / \mathrm{dL}$ was identified, it cannot by itself serve as an independent predictor of postoperative infection in patients with diabetes mellitus because its sensitivity is so low. Future studies should determine what other confounders other than an elevated $\mathrm{HbA} 1 \mathrm{c}$ level contribute to increased infection risk and whether decreasing $\mathrm{HbA} 1 \mathrm{c}$ levels before TKA will decrease the subsequent risk of infection after surgery.

Level of Evidence Level III, diagnostic study.

\section{Introduction}

Lower-extremity total joint arthroplasty procedures are among the fastest-growing procedures performed in the United States [23, 24]. While these procedures are considered safe and cost-effective, periprosthetic joint infection (PJI) after total joint arthroplasty is a rare but devastating complication for patients and their families, and remains a challenging and costly problem to treat, often resulting in permanent disability [14, 20]. Among medical comorbidities of patients undergoing TKA, diabetes mellitus (DM) has been established as one the most common and important disease states associated with an increased risk of postoperative infectious complications [5, 17, 26]. Prior studies have shown higher rates of PJI, wound complications, mortality, increased length of stay, and poorer outcomes in patients with DM undergoing TKA compared with those without DM [15, 17, 19, 26-28, 31, 35-38, 41]. Unfortunately, the prevalence of patients with DM undergoing TKA has been reported to be progressively increasing, and modifiable risk factors in patients with DM need to be identified to mitigate postoperative complications [21, 30, 39].

For patients with DM undergoing TKA, it generally is accepted that maintaining proper glycemic control during the perioperative period is important in potentially reducing the risk of perioperative complications such as PJI. A substantial amount of research has focused on various glycemic markers during the perioperative period and their association with PJI and wound complications in patients with DM undergoing TKA [15-18, 26, 27]. Among these markers, the glycated hemoglobin (HbA1c) level has been used as a common marker for perioperative glycemic control in patients undergoing surgery $[17,18,26,40]$. The HbA1c level is an accessible and objective laboratory value that provides an integrated view of the patient's glycemic status during a 2- to 3-month period [33]. The American Diabetes Association guidelines recommend that patients with $\mathrm{DM}$ maintain an $\mathrm{HbA} 1 \mathrm{c}$ level less than $7 \%$ to minimize systemic complications caused by chronic hyperglycemia [2]. Thus, some prior arthroplasty studies have used an $\mathrm{HbA1c}$ level of $7 \%$ as a cutoff in an attempt to establish a threshold to identify which patients are at higher risk of complications; however, these studies have produced conflicting results and questioned the reliability of this data point as a risk factor for postoperative PJI [1, 18]. Furthermore, other studies have evaluated and suggested thresholds higher than an HbA1c of $7 \%$ to prevent postoperative PJI [16, 17]. However, as a whole, these studies have been limited by low patient numbers that have not allowed an adequately powered analysis and stratification of various HbAlc levels to determine whether such a threshold even exists [16-18, 26].

We therefore asked: (1) Is there an association between perioperative HbA1c level in patients with diabetes and deep postoperative infection after primary TKA? (2) Is there a threshold level of HbA1c above which the risk of deep postoperative infection after TKA increases in patients with diabetes?

\section{Patients and Methods}

\section{Database}

An insurance-based database of patient records, the PearlDiver Patient Records Database (www.pearldiverinc. com, Colorado Springs, CO, USA) was used for this study. The PearlDiver database contains data from Medicare and several different private insurers including UnitedHealthcare and Humana. The data for patients from our study were taken from the Humana database in PearlDiver, since the Humana database is the only one that contains laboratory data among the available databases. The PearlDiver Humana database contains procedural volumes, basic patient demographics and laboratory data, and numerous other data for patients with International Classification of Diseases, 9th Revision (ICD-9) diagnoses and procedures or Current Procedural Terminology (CPT) codes. The database covers patients insured from 2007 to the second quarter of 2015. Overall, the database contains data for approximately 20 million patients with orthopaedic diagnoses. The PearlDiver database has been used in other studies [6,9], however accuracy and attrition of the database is study dependent. In the current study, we were able to look at patients whose records have remained in the database for at least 1 year as evidenced by activity beyond a year. This would represent the absolute minimum number of patients with 1 year followup. For example, there may be a small subset of patients who did not exit the database, but rather did not bill their insurance for the remainder of 
that year in the database. In the current study, the minimum number of patients with 1 year followup was $86 \%$. We believe that this number is an underestimate owing to some patients having a study endpoint at sooner than 1 year, but not having activity past 1 year, and thus not being counted in the 1-year followup. Finally, we thought it appropriate to include all possible patients, as selecting only those with a minimum activity of 1 year in the database would exclude those with early infections, which is an important endpoint in our study. Finally, all data are deidentified and anonymous, therefore this study was exempt from institutional review board approval.

\section{Study Cohort}

The database was first queried for patients who underwent primary TKA using CPT code 27447 and/or ICD-9 procedure code 81.54. To assure that no patients who were undergoing reimplantation of a TKA prosthesis for a previously infected arthroplasty were included in this cohort, all patients with a history of periprosthetic infection (ICD-9 codes 998.51, 998.59, 996.66, 996.69, and/or 996.69), previous arthrotomy for removal of a knee prosthesis (CPT 27488), and/or placement of an antibiotic spacer (ICD-9 procedure codes 80.06 and 84.56 at the same procedure and/or revision TKA CPTs 27486, 27487, 27488, and ICD9 procedure codes $00.80,00.81,00.82,00.83,00.84$ ) were excluded. Patients with a diagnosis of DM (ICD-9 250.xx) who underwent TKA and who had an HbA1c level drawn within 3 months before or after their surgical date then were selected to form the study group. Seventeen thousand four hundred thirty-five patients were identified and then grouped in 13 mutually exclusive groups based on their $\mathrm{HbAlc}$ level by increments of $0.5 \mathrm{mg} / \mathrm{dL}$, starting with patients with a level of $5.49 \mathrm{mg} / \mathrm{dL}$ or less up to patients with a level of $11.5 \mathrm{mg} / \mathrm{dL}$ or greater. For patients with multiple HbA1c levels recorded during the queried time, the level taken closest to the date of surgery was chosen. We then identified 25,105 patients with diabetes who underwent a TKA and did not have an HbAlc during the perioperative window of interest for comparison. We queried each group for several comorbidities attributable to diabetes and demographics using ICD-9 diagnostic codes, including microvascular ischemic disease, peripheral vascular disease, metabolic syndrome, polyneuropathy, gastroparesis, chronic renal failure, chronic kidney disease Stages 1 through 5, end stage renal disease, age younger than 50 years, 50 to 59 years, 60 to 69 years, and 70 to 79 years, and gender (Table 1). Finally a Charlson Comorbidity Index was queried for each group and compared using a Student's t-test. Aside from slightly higher rates of polyneuropathy, chronic renal failure, and chronic kidney disease Stages 2 and 3, the two groups were similar in all other measures studied (Table 1).

\section{Infection}

The endpoint examined in this study was deep infection after TKA requiring surgical intervention within 1 year. Four separate potential procedures were considered in this definition: irrigation and débridement (CPTs 10180, 20005, or 27310), removal of TKA prosthesis (CPT 27488), Stage I TKA (ICD-9 procedure codes 80.06 and 84.56 at the same procedure) and/or revision TKA (CPTs 27486, 27487, 27488, and ICD-9 procedure codes 00.80, 00.81, $00.82,00.83,00.84)$. To assure that only procedures performed for infection were considered, only procedures with an associated diagnosis code for postoperative or periprosthetic infection (ICD-9s 998.51, 998.59, 996.66, 996.69, and/or 996.69) were included. While the use of the associated ICD-9 codes for periprosthetic infection increase the likelihood that the infections included represented true deep infections, there could be some patients who were coded as such who did not have deep infections, such as those with a sterile seroma or hematoma that underwent irrigation and débridement. Each HbA1c level study group then was queried for deep postoperative infection as defined above within 1 year of the index TKA.

\section{Statistical Analysis}

The number of deep postoperative infections requiring surgical intervention was plotted against the HbAlc level group using Microsoft ${ }^{\circledR}$ Excel $^{\circledR}$ (Microsoft Corporation, Redmond, WA, USA) (Fig. 1). These data then were used to construct a receiver operating characteristic (ROC) curve to determine a threshold HbA1c level interval above which the risk of deep postoperative infection was substantially elevated (Fig. 2). This was done by comparing the rate of infection in patients above and below the threshold and performing a chi-square analysis. ROC analysis was performed using SPSS Version 23.0 for Macintosh (IBM Corp, Armonk, NY, USA). Statistical significance of the ROC curve was determined using an area under the curve (AUC) analysis, with a probability less than 0.05 considered statistically significant. The threshold $\mathrm{HbA} 1 \mathrm{c}$ level determined by ROC analysis then was tested using a multivariable binomial logistic regression analysis, in which the deep infection rate in patients with $\mathrm{HbA1c}$ levels less than the threshold level was compared with the infection rate in patients with $\mathrm{HbAlc}$ levels greater than the threshold while controlling for numerous demographic and comorbidity variables that have been 
Table 1. Statistical comparison of patients with diabetes with and without HbAlc values within 3 months of TKA

\begin{tabular}{|c|c|c|c|c|c|}
\hline \multirow[t]{2}{*}{ Variable studied } & \multicolumn{2}{|c|}{ Study (HbA1c within 3 months) } & \multicolumn{2}{|c|}{ Control (no HbA1c within 3 months) } & \multirow[t]{2}{*}{$\mathrm{p}$ Value } \\
\hline & $\begin{array}{l}\text { Number } \\
17,435\end{array}$ & $\begin{array}{l}\% \\
100 \%\end{array}$ & $\begin{array}{l}\text { Number } \\
25,105\end{array}$ & $\begin{array}{l}\% \\
100 \%\end{array}$ & \\
\hline \multicolumn{5}{|l|}{ Diabetes-related complications } & (chi-square analysis) \\
\hline Microvascular ischemic disease & 420 & $2.41 \%$ & 602 & $2.40 \%$ & 0.967 \\
\hline Peripheral vascular disease & 1799 & $10.32 \%$ & 2475 & $9.86 \%$ & 0.125 \\
\hline Metabolic syndrome & 583 & $3.34 \%$ & 769 & $3.06 \%$ & 0.111 \\
\hline Polyneuropathy & 3797 & $21.78 \%$ & 5011 & $19.96 \%$ & $<0.0001$ \\
\hline Gastroparesis & 207 & $1.19 \%$ & 305 & $1.21 \%$ & 0.832 \\
\hline Chronic renal failure & 2405 & $13.79 \%$ & 2944 & $11.73 \%$ & $<0.0001$ \\
\hline Chronic kidney disease Stage 1 & 449 & $2.58 \%$ & 578 & $2.30 \%$ & 0.076 \\
\hline Chronic kidney disease Stage 2 & 1370 & $7.86 \%$ & 1486 & $5.92 \%$ & $<0.0001$ \\
\hline Chronic kidney disease Stage 3 & 2201 & $12.62 \%$ & 2566 & $10.22 \%$ & $<0.0001$ \\
\hline Chronic kidney disease Stage 4 & 365 & $2.09 \%$ & 480 & $1.91 \%$ & 0.199 \\
\hline Chronic kidney disease Stage 5 & 61 & $0.35 \%$ & 73 & $0.29 \%$ & 0.326 \\
\hline End stage renal disease & 109 & $0.63 \%$ & 183 & $0.73 \%$ & 0.224 \\
\hline \multicolumn{6}{|l|}{ Basic demographics } \\
\hline Age $<50$ years & 207 & $1.19 \%$ & 272 & $1.08 \%$ & 0.318 \\
\hline Age $50-59$ years & 1578 & $9.05 \%$ & 2250 & $8.96 \%$ & 0.754 \\
\hline Age $60-69$ years & 6096 & $34.96 \%$ & 9277 & $36.95 \%$ & $<0.0001$ \\
\hline Age $70-79$ years & 7646 & $43.85 \%$ & 10,677 & $42.53 \%$ & 0.006 \\
\hline Age $>80$ years & 1908 & $10.94 \%$ & 2629 & $10.47 \%$ & 0.121 \\
\hline Female & 10,827 & $62.10 \%$ & 15,419 & $61.42 \%$ & 0.155 \\
\hline Male & 6608 & $37.90 \%$ & 9686 & $38.58 \%$ & $\mathrm{n} / \mathrm{a}$ \\
\hline \multirow[t]{2}{*}{ Charlson Comorbidity Index } & & & & & (Student's t test) \\
\hline & $3.81 \pm 3.13$ & $\mathrm{n} / \mathrm{a}$ & $3.78 \pm 2.74$ & $\mathrm{n} / \mathrm{a}$ & 0.295 \\
\hline
\end{tabular}

$\mathrm{n} / \mathrm{a}=$ not applicable.

cited as risk factors for infection [22, 43]. Variables controlled for in the regression included the following patient demographics: age, sex, BMI, tobacco use, alcohol use, and medical comorbidities (including hypertension, hyperlipidemia, coronary artery disease, congestive heart failure, peripheral vascular disease, chronic kidney disease, chronic lung disease, chronic liver disease, inflammatory arthritis, depression, hypercoagulable disorders, thyroid disease, and current hemodialysis use).

\section{Results}

The risk of deep postoperative infection resulting in surgical intervention after TKA in patients with DM increased as the perioperative $\mathrm{HbAlc}$ increased (Fig. 1). The rate of infection ranged from a low of $0.8 \%$ for patients with an $\mathrm{HbA} 1 \mathrm{c}$ of $5.49 \mathrm{mg} / \mathrm{dL}$ and less up to $3.5 \%$ for patients with a $\mathrm{HbA} 1 \mathrm{c}$ level greater than $11.5 \mathrm{mg} / \mathrm{dL}$.

The inflection point of the ROC curve corresponded to an $\mathrm{HbA} 1 \mathrm{c}$ level between 7.5 and $8.0 \mathrm{mg} / \mathrm{dL}(\mathrm{p}=0.025$; specificity $=77 \%$; sensitivity $=32 \%$ ), indicating that 8.0 $\mathrm{mg} / \mathrm{dL}$ might serve as a threshold for increased risk of deep infection (Fig. 2). This ROC curve was an unadjusted analysis of HbA1c plotted against deep infection data as this is the most appropriate way to determine if an $\mathrm{HbA1c}$ level alone is useful for decision making. Patients with an HbA1c level of $8.0 \mathrm{mg} / \mathrm{dL}$ or greater were more likely to have an infection develop within 1 year of TKA than those who had HbA1c levels less than $8.0 \mathrm{mg} / \mathrm{dL}$ (1.63\% [41 of 2514 ] vs $0.98 \%$ [147 of 14,921]; adjusted odds ratio, 1.7 ; 95\% CI, 1.2-2.4; $\mathrm{p}=0.004)$. However, our AUC analysis of 0.548 (95\% CI, $0.50-0.59 ; \mathrm{p}=0.025)$ indicated that while we were able to identify a threshold, the accuracy of this threshold as an independent predictor for postoperative infection after TKA was poor and of limited clinical utility.

\section{Discussion}

Numerous authors have identified DM as a risk factor for wound complications and PJI in patients undergoing TKA $[12,15,19,31,35,36,41]$. Although it is known that achieving proper glycemic control during the perioperative 
Fig. 1 The rate of deep infection after primary TKA within 1 year stratified by $\mathrm{HbA} 1 \mathrm{c}$ level within 3 months of surgery is shown.

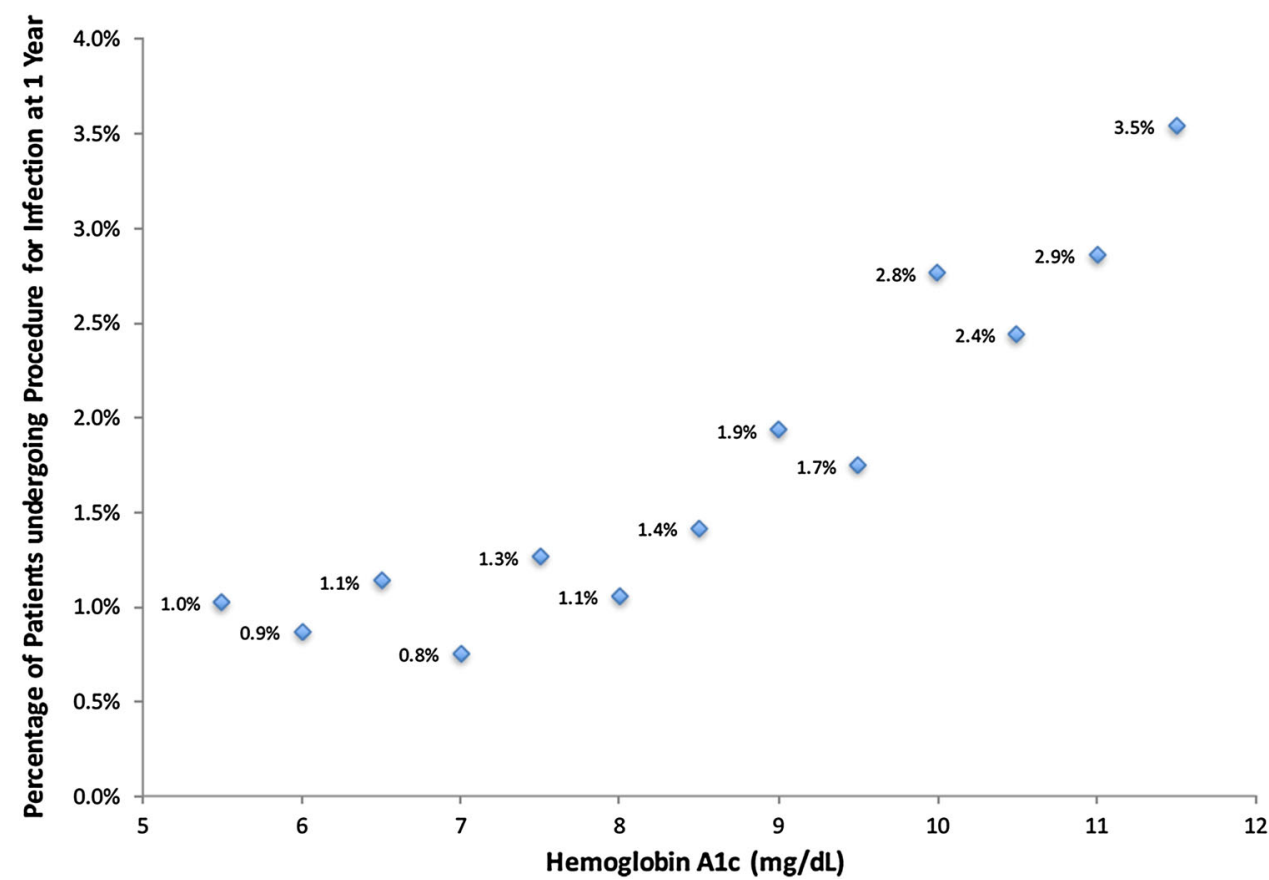

period is important, evidence to support a threshold level of HbAlc above which the risk of postoperative infection after TKA increases in patients with diabetes has yet to be definitively established. In the current study we showed an increasing risk of deep postoperative infection requiring surgical intervention after TKA in patients with DM as the HbA1c level increases. Furthermore, while a ROC analysis determined that an $\mathrm{HbA} 1 \mathrm{c}$ level greater than $8.0 \mathrm{mg} / \mathrm{dL}$ might serve as a threshold for an increased risk of deep postoperative infection after TKA, our AUC analysis indicated that the accuracy of this threshold as an independent predictor for postoperative infection after TKA was poor and of limited clinical utility.

Our study has several limitations, many of which are inherent to all studies using large administrative databases $[3,7,8]$. First, the power of our analysis relies on the quality of the available data and the accuracy of procedural coding in the database. Thus, miscoding and noncoding by physicians are potential sources of error. As previously discussed, we do believe that the use of associated ICD-9 codes for periprosthetic infection increases the likelihood that the infections included represent true deep infections requiring operative treatment. However, there might be situations where patients were coded as having such infections and after further evaluation or definitive treatment the final diagnosis was changed to a noninfectious cause. Although there are no data reflecting the coding accuracy in the Humana dataset, coding errors in the Medicare population are estimated to be approximately $1.3 \%$ [10]. Therefore, although this is a major potential limitation when using administrative databases such as
PearlDiver, the overall coding error rate likely mirrors that in larger Medicare populations. Second, there is an inevitable amount of attrition or leakage that occurs from all registries such as the PearlDiver database, and these studies must be viewed in the context of this limitation $[3,7,32]$. As earlier noted, we have estimated the absolute minimum number of patients with 1 year followup for the current study to $86 \%$. However, this is likely an underestimate as some patients had a study endpoint of infection sooner than 1 year, and then may not have had any activity past 1 year, and thus would not be captured in this estimate. We believe it is appropriate to include these patients, as selecting only those with a minimum of 1 year of activity might preclude some patients with early infections, which are endpoints of interest. Third, although DM has been shown to be an important risk factor for PJI developing after TKA, and this was identified again here, there are several other factors that also affect infection risk that are unable to be characterized in the database. These include operative time, indication for surgery, antibiotic cement use, hospital volume, and tourniquet use, among others. This is further evidenced by the results of our AUC analysis, which showed that the HbAlc level alone is not a reliable predictor for deep infection after TKA in these patients, and the cause is likely multifactorial. The statistical package in the PearlDiver database allows limited analyses of the obtained data. While we were able to perform a logistic regression and control for covariates to further evaluate the threshold from the ROC curve, more sophisticated analyses such as bootstrapping were not possible. Thus, the threshold must be evaluated with this 


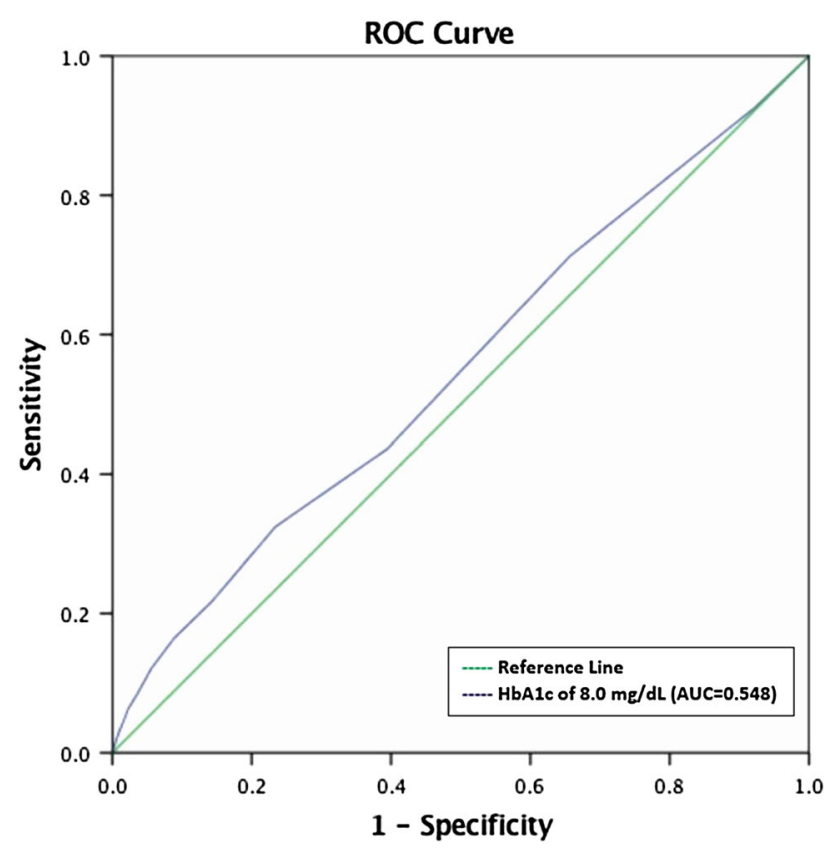

Fig. 2 The receiver operating characteristic (ROC) curve was used to determine a threshold above which the risk of deep postoperative infection was substantially elevated.

limitation in mind. Fourth, although we attempted to accurately represent a large population of interest by using this database, we cannot assure that the database represents a true cross section of the United States population with diabetes, as only one insurer's data were included in the analysis. However, we found substantially lower rates of several diabetic-induced complications, such as microvascular ischemic disease and polyneuropathy, in our study population with diabetes compared with other published rates in the general population with diabetes $[4,11,29,34,42]$. Finally, the findings in our study represent PJI requiring return of patients to the operating room within 1 year of TKA to increase the likelihood that the infection was related to the perioperative management of the TKA, and not another condition or medical or surgical issue that arose. Thus, late infections outside this postoperative window are not captured in our study, which should be considered to describe the risk only during the first postoperative year.

Although diabetes has been well established as a risk factor for postoperative infection after TKA, available evidence regarding the effect of perioperative HbA1c levels on postoperative infection is conflicting. In the current study we were able to sufficiently power an analysis of more than 17,000 patients with DM undergoing TKA to show an increasing risk of deep postoperative infection with increasing perioperative HbA1c levels. This is in contrast to several other studies. Iorio et al. [18] reviewed 2479 primary TKAs and compared patients with and without diabetes and found no association between
$\mathrm{HbA} 1 \mathrm{c}$ and postoperative infection, leading them to suggest that this marker is not predictive for deep infection after surgery. Adams et al. [1] studied more than 7567 patients with diabetes who underwent primary TKA and also found no association between preoperative $\mathrm{HbA} 1 \mathrm{c}$ and postoperative infection, and suggested that other factors besides glycemic control, such as BMI or other comorbid conditions, might be more strongly predictive of infectious complications than HbA1c. Finally, Maradit Kremers et al. [26] reviewed 10,451 TKAs and also found no association with the development of PJI and HbA1c as either a continuous variable or a dichotomized cutoff value of $7 \mathrm{mg} /$ dL. However, in contrast to the above findings, and in agreement with the current study, Stryker et al. [40] reviewed 22 TKAs and reported an increased postoperative risk for wound complications with increasing $\mathrm{HbA} 1 \mathrm{c}$ values. These findings were substantiated by Jamsen et al. [19] who reviewed 1565 patients undergoing TKA and found a direct correlation between patients with $\mathrm{HbA1c}$ levels greater than $6.5 \mathrm{mg} / \mathrm{dL}$ and postoperative infection. We propose that the inability to associate increasing HbAlc with an increasing risk of deep infection in prior studies is largely attributable to inadequate sample size which limits the stratification of HbAlc as a categorical variable. Current studies that support and refute the idea that an increasing $\mathrm{HbAlc}$ raises infection risk group patients above and below a selected $\mathrm{HbA1c}$ value and then compare infection risk [1, 26, 40]. By sampling more than 17,000 patients we could compare multiple $\mathrm{HbA1c}$ points to show an increasing risk of infection with increasing values.

Given the increasing incidence of diabetes among patients undergoing TKA [25, 30], and the enormous financial and personal burdens of PJI, it is critical to identify patients for TKA who are at greater risk for this complication by using clinically accessible and objective risk markers such as $\mathrm{HbAlc}$ level. We therefore sought to determine whether any particular HbAlc threshold could identify patients at particular risk for PJI. Although we found that patients with an $\mathrm{HbA} 1 \mathrm{c}$ greater than $8.0 \mathrm{mg} / \mathrm{dL}$ are at increased risk, this threshold offered poor sensitivity (32\%) and intermediate (77\%) specificity, and so is not adequate to be used in isolation. Several other studies also have attempted to evaluate various threshold $\mathrm{HbA} 1 \mathrm{c}$ levels for predicting postoperative infection with conflicting results [15-17]. Harris et al. [16] reported on a cohort of 6088 patients with diabetes from the Veterans Health Administration undergoing total joint arthroplasty and analyzed the functional relationship between $\mathrm{HbA} 1 \mathrm{c}$ and complications. They suggested that a presurgical HbAlc of $7 \%$ or greater was associated with an increased risk of having at least one surgical complication. However, after performing an analysis using various thresholds from 5\% to 
$9 \%$, they suggested that although lower values of $\mathrm{HbA} 1 \mathrm{c}$ generally are associated with lower risk of complications, there was nothing particularly unique about a 7\% threshold that has been used by others $[1,18]$. In an extrapolated model the risk appeared to increase slowly up to $6.5 \%$, and then rise linearly thereafter, without a discrete cutoff value above which risk jumped substantially. A major limitation of the study was the use of presurgical $\mathrm{HbA} 1 \mathrm{c}$ values recorded up to a year before surgery, in addition to grouping complications, such as wound infection and PJI, among other medical complications.

Other studies have examined higher $\mathrm{HbAlc}$ thresholds and their association with infection- specific complications $[15,17]$. Hwang et al. [17] retrospectively studied 464 patients with DM who underwent a total of 714 TKAs and found that an $\mathrm{HbA} 1 \mathrm{c}$ of $8 \%$ or greater was associated with an increased risk (odds ratio [OR]. 6.1; 95\% CI, 1.6-23.4; $\mathrm{p}$ $=0.008$ ) of superficial surgical site infection, although no patients had a deep infection resulting in return to the operating room. Furthermore, they concluded that an increasing risk for superficial infection is found with increasing $\mathrm{HbAlc}$ levels, and suggested that the threshold level is likely higher than the 7\% level suggested by others $[1,18]$. This is in agreement with a study by Han and Kang [15], who also reported an association between $\mathrm{HbAlc}$ levels of $8 \%$ or greater and wound complications but no association with deep infection requiring subsequent procedures. However, a major limitation of their study is the low number of patients with diabetes who underwent a total of 714 TKAs. Consequently, they were unable to perform an analysis of patients with deep infection resulting in return to the operating room as an endpoint, because there were no patients with this complication in their cohort. Furnes [13], in a study from the Norwegian Arthroplasty Registry, reported that 13,373 procedures would be necessary to detect a difference of one percentage point in revision rate between two groups. This substantial sample size is likely unobtainable from a single retrospective institutional database. In the current study, by using a national database, we were able to review more than 17,000 patients with DM who underwent TKA. By evaluating this large number of patients we found that as HbAlc levels increase, so does the risk of return to the operating room to treat deep prosthetic infection. While prior studies have identified $\mathrm{HbAlc}$ thresholds, limited patient numbers have prevented an adequate evaluation of these thresholds as independent discriminators for postoperative infection and thus their clinical utility remains largely unknown [15-17]. In the current study we were able to identify and evaluate a threshold indicated from our ROC analysis and found that $\mathrm{HbAlc}$ as a stand-alone laboratory value is a poor predictor of PJI.
We believe that although an HbA1c level greater than $8.0 \mathrm{mg} / \mathrm{dL}$ is helpful and should be referenced when stratifying a patient's infection risk, it must be interpreted in the context of the patient's other risk factors for PJI. Furthermore, we suggest obtaining an updated HbAlc level before TKA in patients with diabetes as there is an increasing risk of infection with higher $\mathrm{HbAlc}$ levels. Further research is needed to examine potential confounders associated with glycemic control that affect infection risk, and how these could be combined to create a more accurate and clinically useful picture of infection risk in patients with diabetes. Additional research also is needed to determine whether modifying HbAlc levels before TKA will decrease the subsequent risk of infection after TKA.

Acknowledgments We thank Wendy Novicoff $\mathrm{PhD}$ (Department of Orthopaedic Surgery, University of Virginia), for assistance with the statistical and analytics portion of this study.

\section{References}

1. Adams AL, Paxton EW, Wang JQ, Johnson ES, Bayliss EA, Ferrara A, Nakasato C, Bini SA, Namba RS. Surgical outcomes of total knee replacement according to diabetes status and glycemic control, 2001 to 2009. J. Bone Joint Surg. Am. 2013;95:481-487.

2. American Diabetes Association. Update of ADA's major position statement, "Standards of Medical Care in Diabetes". Introduction. Diabetes Care. 2011;34(suppl 1):S1-2.

3. Bedard NA, Pugely AJ, Elkins JM, Duchman KR, Westermann RW, Liu SS, Gao Y, Callaghan JJ. The John N. Insall Award: Do Intraarticular Injections Increase the Risk of Infection After TKA? Clin Orthop Relat Res. 2017;475:45-52.

4. Bener A, Al-Laftah F, Al-Hamaq AO, Daghash M, Abdullatef WK. A study of diabetes complications in an endogamous population: an emerging public health burden. Diabetes Metab Syndr. 2014;8:108-114.

5. Bolognesi MP, Marchant MH Jr, Viens NA, Cook C, Pietrobon $\mathrm{R}$, Vail TP. The impact of diabetes on perioperative patient outcomes after total hip and total knee arthroplasty in the United States. J Arthroplasty. 2008;23(6 suppl 1):92-98.

6. Cancienne JM, Brockmeier SF, Werner BC. Tobacco use is associated with increased rates of infection and revision surgery after primary superior labrum anterior and posterior repair. $J$ Shoulder Elb Surg. 2016;25:1764-1768.

7. Cancienne JM, Dempsey IJ, Holzgrefe RE, Brockmeier SF, Werner BC. Is hepatitis $\mathrm{C}$ infection associated with a higher risk of complications after total shoulder arthroplasty? Clin Orthop Relat Res. 2016;474:2664-2669.

8. Cancienne JM, Gwathmey FW, Miller MD, Werner BC. Tobacco use is associated with increased complications after anterior cruciate ligament reconstruction. Am J Sports Med. 2016;44:99104.

9. Cancienne JM, Gwathmey FW, Werner BC. Intraoperative corticosteroid injection at the time of knee arthroscopy is associated with increased postoperative infection rates in a large Medicare population. Arthroscopy. 2016;32:90-95.

10. Centers for Medicare and Medicaid Services. Medicare Fee - for Service 2012 Improper Payments Report. Available at: https:// www.cms.gov/Research-Statistics-Data-and-Systems/Monitoring- 
Programs/CERT/Downloads/MedicareFeeforService2012Impro perPaymentsReport.pdf. Accessed January 10, 2017.

11. Deshpande AD, Harris-Hayes M, Schootman M. Epidemiology of diabetes and diabetes-related complications. Phys Ther. 2008;88:1254-6124.

12. England SP, Stern SH, Insall JN, Windsor RE. Total knee arthroplasty in diabetes mellitus. Clin Orthop Relat Res 1990; 260:130-134

13. Furnes ON. Hip and Knee Replacement in Norway 1987-2000. The Norwegian Arthroplasty Register. (PhD Thesis). Available at: http://www.ear.efort.org/downloads/drgradove.pdf. Accessed September 21, 2016.

14. Gomez MM, Tan TL, Manrique J, Deirmengian GK, Parvizi J. The fate of spacers in the treatment of periprosthetic joint infection. J Bone Joint Surg Am. 2015;97:1495-502.

15. Han HS, Kang SB. Relations between long-term glycemic control and postoperative wound and infectious complications after total knee arthroplasty in type 2 diabetics. Clin Orthop. Surg. 2013;5:118-123.

16. Harris AH, Bowe TR, Gupta S, Ellerbe LS, Giori NJ. Hemoglobin $\mathrm{A} 1 \mathrm{C}$ as a marker for surgical risk in diabetic patients undergoing total joint arthroplasty. J Arthroplasty. 2013;28(8 suppl):25-29.

17. Hwang JS, Kim SJ, Bamne AB, Na YG, Kim TK. Do glycemic markers predict occurrence of complications after total knee arthroplasty in patients with diabetes? Clin Orthop Relat Res. 2015;473:1726-1731.

18. Iorio R, Williams KM, Marcantonio AJ, Specht LM, Tilzey JF, Healy WL. Diabetes mellitus, hemoglobin A1C, and the incidence of total joint arthroplasty infection. $J$ Arthroplasty. 2012;27:726-729.e1.

19. Jämsen E, Nevalainen P, Eskelinen A, Huotari K, Kalliovalkama J, Moilanen T. Obesity, diabetes, and preoperative hyperglycemia as predictors of periprosthetic joint infection: a single-center analysis of 7181 primary hip and knee replacements for osteoarthritis. J Bone Joint Surg Am. 2012;94:e101.

20. Kapadia BH, Banerjee S, Cherian JJ, Bozic KJ, Mont MA. The economic impact of periprosthetic infections ater total hip arthroplasty at a specialized tertiary-care center. J Arthroplasty. 2016;31:1422-1426.

21. Kim HA, Kim S, Seo YI, Choi HJ, Seong SC, Song YW, Hunter $\mathrm{D}$, Zhang Y. The epidemiology of total knee replacement in South Korea: national registry data. Rheumatology (Oxford). 2008;47:88-91.

22. Kong L, Cao J, Zhang Y, Ding W, Shen Y. Risk factors for periprosthetic joint infection following primary total hip or knee arthroplasty: a meta-analysis. Int Wound J. 2016 Jul 10. [Epub ahead of print] doi: 10.1111/iwj.12640.

23. Kurtz SM, Lau E, Ong K, Zhao K, Kelly M, Bozic KJ. Future young patient demand for primary and revision joint replacement: national projections from 2010 to 2030. Clin Orthop Relat Res. 2009;467:2606-2612.

24. Kurtz SM, Ong KL, Lau E, Bozic KJ. Impact of the economic downturn on total joint replacement demand in the United States: updated projections to 2021. J Bone Joint Surg Am. 2014;96:624630.

25. Labek G. CORR Insights ${ }^{\circledR}$ : Do glycemic markers predict occurrence of complications after total knee arthroplasty in patients with diabetes? Clin Orthop Relat Res. 2015;473:17321734.

26. Maradit Kremers H, Lewallen LW, Mabry TM, Berry DJ, Berbari EF, Osmon DR. Diabetes mellitus, hyperglycemia, hemoglobin $\mathrm{A} 1 \mathrm{C}$ and the risk of prosthetic joint infections in total hip and knee arthroplasty. J Arthroplasty. 2015;30:439-443.

27. Marchant MH Jr, Viens NA, Cook C, Vail TP, Bolognesi MP. The impact of glycemic control and diabetes mellitus on perioperative outcomes after total joint arthroplasty. J Bone Joint Surg Am. 2009;91:1621-1629.

28. Meding JB, Reddleman K, Keating ME, Klay A, Ritter MA, Faris $\mathrm{PM}$, Berend ME. Total knee replacement in patients with diabetes mellitus. Clin Orthop Relat Res. 2003;416:208-216.

29. Melton LJ 3rd, Macken KM, Palumbo PJ, Elveback LR. Incidence and prevalence of clinical peripheral vascular disease in a population-based cohort of diabetic patients. Diabetes Care. $3: 650-654$.

30. Memtsoudis SG, Della Valle AG, Besculides MC, Gaber L, Laskin R. Trends in demographics, comorbidity profiles, inhospital complications and mortality associated with primary knee arthroplasty. J Arthroplasty. 2009;24:518-527.

31. Namba RS, Inacio MCS, Paxton EW. Risk factors associated with deep surgical site infections after primary total knee arthroplasty: an analysis of 56,216 knees. J Bone Joint Surg Am. 2013;95:775782 .

32. Natsuhara KM, Yeranosian MG, Cohen JR, Wang JC, McAllister DR, Petrigliano FA. What is the frequency of vascular injury after knee dislocation? Clin Orthop Relat Res. 2014;472:26152620.

33. O'Keeffe DT, Maraka S, Rizza RA. HbA1c in the evaluation of diabetes mellitus. JAMA. 2016;315:605-606.

34. Perkovic V, Agarwal R, Fioretto P, Hemmelgarn BR, Levin A, Thomas MC, Wanner C, Kasiske BL, Wheeler DC, Groop PH; Conference Participants. Management of patients with diabetes and CKD: conclusions from a "Kidney Disease: Improving Global Outcomes" (KDIGO) Controversies Conference. Kidney Int. 2016;90:1175-1183.

35. Pruzansky JS, Bronson MJ, Grelsamer RP, Strauss E, Moucha CS. Prevalence of modifiable surgical site infection risk factors in hip and knee joint arthroplasty patients at an urban academic hospital. J Arthroplasty. 2014;29:272-276.

36. Reátegui D, Sanchez-Etayo G, Núñez E, Tió M, Popescu D, Núñez M, Lozano L. Perioperative hyperglycaemia and incidence of post-operative complications in patients undergoing total knee arthroplasty. Knee Surg Sports Traumatol Arthrosc. 2015;23: 2026-2031.

37. Robertson F, Geddes J, Ridley D, McLeod G, Cheng K. Patients with Type 2 diabetes mellitus have a worse functional outcome post knee arthroplasty: a matched cohort study. Knee. 2012;19: 286-289.

38. Singh JA, Lewallen DG. Diabetes: a risk factor for poor functional outcome after total knee arthroplasty. PLoS One. 2013;8: e78991.

39. Singh JA, Sloan J. Higher comorbidity, poor functional status and higher health care utilization in veterans with prevalent total knee arthroplasty or total hip arthroplasty. Clin Rheumatol. 2009;28: 1025-1033.

40. Stryker LS, Abdel MP, Morrey ME, Morrow MM, Kor DJ, Morrey BF. Elevated postoperative blood glucose and preoperative hemoglobin $\mathrm{A} 1 \mathrm{C}$ are associated with increased wound complications following total joint arthroplasty. J Bone Joint Surg Am. 2013;95:808-814.

41. Yang K, Yeo SJ, Lee BP, Lo NN. Total knee arthroplasty in diabetic patients: a study of 109 consecutive cases. J Arthroplasty. 2001;16:102-106.

42. Yokoyama H, Oishi M, Takamura H, Yamasaki K, Shirabe S, Uchida D, Sugimoto H, Kurihara Y, Araki S, Maegawa H. Largescale survey of rates of achieving targets for blood glucose, blood pressure, and lipids and prevalence of complications in type 2 diabetes (JDDM 40). BMJ Open Diabetes Res Care. 2016;4:e00294.

43. Zhu Y, Zhang F, Chen W, Liu S, Zhang Q, Zhang Y. Risk factors for periprosthetic joint infection after total joint arthroplasty: a systematic review and meta-analysis. J Hosp Infect. 2015;89:8289. 